\title{
Study of major genetic factors involved in pituitary tumorigenesis and their impact on clinical and biological characteristics of sporadic somatotropinomas and non-functioning pituitary adenomas
}

\author{
R.K. Foltran ${ }^{1}$, P.V.G.H. Amorim ${ }^{1}$, F.H. Duarte ${ }^{2,5}$, I.P.P. Grande ${ }^{1}$, A.C.T.B. Freire ${ }^{2}$, F.P. Frassetto ${ }^{3}$, \\ J.B. Dettoni ${ }^{3}$, V.A. Alves ${ }^{3}$, I. Castro ${ }^{4}$, E.B. Trarbach ${ }^{1,2}$, M.D. Bronstein ${ }^{1,2}$ and R.S. Jallad ${ }^{1,2}$ \\ ${ }^{1}$ Laboratorio de Endocrinologia Celular e Molecular, LIM25, Disciplina de Endocrinologia, Hospital das Clínicas, \\ Faculdade de Medicina, Universidade de São Paulo, São Paulo, SP, Brasil \\ ${ }^{2}$ Unidade de Neuroendocrinologia, Disciplina de Endocrinologia, Hospital das Clínicas, Faculdade de Medicina, \\ Universidade de São Paulo, São Paulo, SP, Brasi \\ ${ }^{3}$ Divisao de Anatomia Patológica, Hospital das Clínicas, Faculdade de Medicina, Universidade de São Paulo, São Paulo, \\ SP, Brasi \\ ${ }^{4}$ Divisao de Medicina Molecular, Departamento de Medicina, Hospital das Clínicas, Faculdade de Medicina, \\ Universidade de São Paulo, São Paulo, SP, Brasil \\ ${ }^{5}$ Serviço de Endocrinologia, A.C. Camargo Center, São Paulo, SP, Brasil
}

\begin{abstract}
Genetic and functional aberrations of guanine nucleotide-binding protein, alpha stimulating (GNAS), aryl hydrocarbon receptor interacting protein (AIP), and pituitary tumor transforming gene (PTTG) are among the most prominent events in pituitary tumorigenesis. A cohort of Brazilian patients with somatotropinomas $(n=41)$ and non-functioning pituitary adenomas (NFPA, $n=21)$ from a single tertiary-referral center were evaluated for GNAS and AIP mutations and gene expression of AIP and PTTG. Results were compared to the clinical and biological (Ki67 and p53 expression) characteristics of tumors and their response to therapy, if applicable. Genetic analysis revealed that $27 \%$ of somatotropinomas and $4.8 \%$ of NFPA harbored GNAS mutations $(P=0.05)$. However, no differences were observed in clinical characteristics, tumor extension, response to somatostatin analog therapy, hormonal/surgical remission rates, Ki67 index, and p53 expression between mutated and non-mutated somatotropinomas patients. $P T T G$ overexpression $(R Q$ mean $=10.6, \min =4.39$, max=11.9) and $A I P$ underexpression $(R Q$ mean $=0.56$, min $=0.46-$ $\max =0.92$ ) were found in virtually all cases without a statistically significant relationship with clinical and biological tumor features. No patients exhibited somatic or germline pathogenic AIP mutations. In conclusion, mutations in GNAS and abnormal PTTG and AIP expression had no impact on tumor features and treatment outcomes in this cohort. Our data support some previous studies and point to the need for further investigations, probably involving epigenetic and transcriptome analysis, to improve our understanding of pituitary tumor behavior.
\end{abstract}

Key words: Somatotropinomas; Non-functioning pituitary adenomas; PTTG; AIP; GNAS1

\section{Introduction}

Pituitary adenomas are mostly sporadic and result from genetic mutations in a single cell involving overexpression of oncogenes, inactivation of tumor suppressor genes, and alterations of transcription factors regulating cell growth and differentiation $(1,2)$. An abnormal response to hypothalamic stimulation can provide a permissive environment for molecular events to occur within the pituitary gland. However, the precise mechanisms of tumorigenesis remain unclear $(1,2)$.
Proto-oncogenes GNAS (guanine nucleotide-binding protein, alpha stimulating), PTTG (pituitary tumor-transforming gene 1), and tumor suppressor gene AIP (aryl-hydrocarbon receptor-interacting protein) are the most prominent genetic factors involved in pituitary tumorigenesis and have been implicated in the development of somatotropinomas and non-functioning pituitary adenomas (NFPA) (2). In addition, a recent meta-analysis study points to a putative role for GNAS1 mutation as a prognostic factor of treatment 
response to somatostatin receptor ligands (3). Nevertheless, the importance of GNAS1, PTTG, and AIP as molecular markers in the prognosis of pituitary adenomas is still controversial (4-7).

In this study, we assessed the presence of GNAS and AIP mutations as well as altered gene expressions of AIP and PTTG in sporadic somatotropinomas and NFPA patients admitted to a single endocrine tertiary-referral center. The importance of these genetic factors, Ki-67 cell proliferation marker, and p53 on the prognosis of pituitary adenomas was also evaluated.

\section{Material and Methods}

Patient information regarding age, hormone levels, family background, and tumor characteristics (size and extension) at diagnosis was retrospectively obtained from medical records. Histopathologic analyses and follow-up data after surgery were recorded for each patient. After surgery, clinical, hormonal, and radiological data were evaluated. Tumor size was measured as the maximum diameter on MRI and tumors were classified accordingly as microadenomas $(<10 \mathrm{~mm}$ ) or macroadenomas $(\geqslant 10 \mathrm{~mm})$. Treatment and follow-up were based on physician discretion in accordance with current guidelines (8). For all patients, transsphenoidal surgery was the primary therapy for acromegaly. No patient underwent radiotherapy. After non-effective pituitary surgery, somatostatin receptor ligand (octreotide LAR) and/or dopamine agonist (cabergoline) were used in acromegalic patients to achieve hormonal and/or tumor control. The last follow-up data, including patients treated with different therapies, were analyzed to define clinical status regarding remission and disease activity. For acromegaly, controlled disease criteria were normal age-adjusted insulin-like growth factor-1 (IGF-1) concentrations and a random growth hormone $(\mathrm{GH})<1 \mathrm{ng} / \mathrm{mL}$. For NFPAs, tumor control was based on either the complete resection of tumor, size stability or reduction of the lesion on MRI; in cases with incomplete primary resection, tumor stability was assessed in terms of tumor remnant behavior.

This study was approved by the Hospital das Clínicas, Faculdade de Medicina, Universidade de São Paulo ethics committee and all patients signed an informed consent form.

\section{Extraction of nucleic acid}

DNA and RNA were extracted from fresh tumor cryosections using All Prep DNA/RNA Mini Kit (Qiagen, USA) according to manufacturer's protocol. DNA and RNA were used for genetic mutations and gene expression analysis, respectively. DNA extraction from blood was performed using DNeasy blood kit (Qiagen) according to manufacturer's protocol.

\section{Sanger sequencing and in silico analysis}

All coding regions of AIP and hotspots of exons 8 and 9 of GNAS were amplified by polymerase chain reaction
(PCR) as previously described, using tissue and tissue/ germline DNA, respectively $(9,10)$. Sequences obtained were compared with sequences in the Ensemble database (AIP, ENST00000279146 and GNAS, ENST00000371100) using Sequencher 3.0 software (Gene Codes, USA).

All variants identified were confirmed in two independent PCR products and sequencing of both strands. In silico predictions were performed only for rare variants using NetGene2 (http://www.cbs.dtu.dk/services/Net Gene2/) and Human Splicing Finder (HSF, www.umd. be/HSF3).

\section{RNA expression}

cDNA was synthesized using $1 \mu \mathrm{g}$ of RNA by QuantiTect Reverse Transcription (Qiagen) following manufacturer's instructions. RNA quantification was performed in Step One Plus ${ }^{\mathrm{TM}}$ Real-Time PCR system (Applied Biosystems, USA) using PTTG (Hs00864094_g1) and AIP (Hs00610222_m1) TaqMan ${ }^{\circledR}$ assays (Applied Biosystems) according to the manufacturer's instructions. Relative quantification was calculated by $2^{-\Delta \Delta C T}$ method using HPRT1 as an endogenous gene (Hs02800695_m1, Applied Biosystems) and a commercial pool of RNA from human pituitary gland (Clontech, USA) as calibrator (11).

\section{Immunohistochemistry}

Standard immunohistochemical reactions were carried out on formalin-fixed paraffin-embedded tissue to evaluate the presence of anterior pituitary hormones $(\mathrm{GH}, \mathrm{PRL}$, $\mathrm{LH}, \mathrm{FSH}, \mathrm{TSH}$, and $\mathrm{ACTH}$ ), Ki-67 (anti-human antigen Ki67, clone MIB-1, DAKO, cod. M7240, Denmark), and p53 (anti-human p53 protein, clone 318-6-11, DAKO, cod. M3629). For pituitary hormones, immunostaining was routinely performed in the Departmento de Patologia, Divisão do Laboratório Central, Hospital das Clínicas, Universidade de São Paulo (Brazil). The Ki-67 proliferative index was determined as the percentage of labeled nuclei cells. Ki67 and p53 nuclear staining was assessed in approximately 100 cells in 5 randomly chosen visual fields at $\times 400$ magnification. The $\mathrm{Ki}-67$ index was calculated from the mean of stained cells and considered high if $>3$ (12). p53 expression was considered positive in patients with more than $10 \%$ of stained cells. These analyses were blinded and performed by two independent pathologists.

\section{Statistical analysis}

Continuous variables were tested for normality with the Kolmogorov-Smirnov and Shapiro Wilk tests, and are reported as means $\pm S D$ and median $\left(25^{\text {th }}\right.$ and $75^{\text {th }}$ percentiles) according to parametric or non-parametric distribution, respectively. Parametric data were compared using ANOVA. Non-parametric data were compared using the Mann-Whitney $U$ test for two independent samples or Kruskal-Wallis test with Dwass-Steel-Chritchlow-Fligner post hoc test for three or more samples. Categorical data 
Table 1. Summary of clinical, molecular, and immunohistochemical data of patients with somatotropinomas and non-functioning pituitary adenomas (NFPA) evaluated in this study.

\begin{tabular}{lccc}
\hline & Somatotropinomas & NFPA & Total \\
\hline Gender (female:male) & $27: 14$ & $14: 7$ & $41: 21$ \\
Age at diagnosis & $40.3 \pm 15.3$ & $48.4 \pm 11.0$ & $42.9 \pm 14.4$ \\
Basal GH (ng/mL) & $18.9(6.2-75.4)$ & $\mathrm{NA}$ & $\mathrm{NA}$ \\
Basal IGF-1 (ng/mL) & $964.5 \pm 280.5$ & $\mathrm{NA}$ & $\mathrm{NA}$ \\
ULNR-IGF-1 \% & $374.0(297.0-435.0)$ & $\mathrm{NA}$ & $\mathrm{NA}$ \\
Tumor size & & & \\
$\quad$ Largest diameter & $2.27 \pm 1.21$ & $2.96 \pm 1.05$ & $2.49 \pm 1.21$ \\
Micro x macro & $4: 37$ & $0: 21$ & $4: 58$ \\
Invasiveness (yes:no) & $25: 16$ & $12: 9$ & $37: 25$ \\
Tumor remission (yes:no) & $11: 20$ & $11: 3$ & $30: 13$ \\
Hormonal remission (yes:no) & $26: 15$ & $\mathrm{NA}$ & $\mathrm{NA}$ \\
GNAS mutations & & & \\
p.R201C & 9 & 1 & 10 \\
p.Q227L & 1 & 0 & 1 \\
p.Q227R & 1 & 0 & 0 \\
AIP mutations & 0 & 0 & $0.56(0.46-0.92)$ \\
AIP RQ & $0.62(0.43-0.85)$ & $0.53(0.51-1.28)$ & $10.6(4.39-11.9)$ \\
PTTG RQ & $7.77(4.39-11.9)$ & $12.4(10.1-16.2)$ & $1.32(1-4.5)$ \\
Ki67 (\%)* & $1.32(1-4.5)$ & $1.24(1-3.8)$ & $1.1(1-1.8)$ \\
p53 (\%) & $1.0(1-1.4)$ & $1.1(1-1.8)$ & \\
\hline
\end{tabular}

Data are reported as means \pm SD and median $\left(25^{\text {th }}\right.$ and $75^{\text {th }}$ percentiles). *Mean, minimum, and maximum values are reported for Ki67 index and p53. GH: growth hormone; IGF-1: insulin-like growth factor-l; ULNR: upper limit of the normal age- and sex-matched range; GNAS: guanine nucleotide-binding protein, alpha stimulating; AIP: aryl hydrocarbon receptor interacting protein; PTTG: pituitary tumor transforming gene; $\mathrm{RQ}$ : relative quantification; NA: not applicable.

were analyzed using Pearson's chi-squared test and Fisher's exact test where applicable, and are reported as absolute values or percentages. Correlations were calculated using the Spearman rank test. Statistical significance was considered to be $P \leqslant 0.05$. Analyses were performed using SPSS 19.0 (IBM Analytics, USA) and Stata/SE 14.2 (StataCorp LLC, USA).

\section{Results}

\section{Patient characteristics}

Sixty-two patients with apparently sporadic pituitary adenomas (41 somatotropinomas and 21 NFPA) were evaluated. All patients' clinical symptoms were consistent with the diagnostic criteria that was confirmed by clinical, imaging, and pathology data related to each pituitary tumor subtype. Table 1 shows a summary of clinical, molecular, and immunohistochemical data of the somatotropinomas and NFPA patients evaluated.

\section{GNAS mutations}

GNAS (p.Q227L, n=1; p.Q227R, $n=1$ and p.R201C, $\mathrm{n}=9$ ) somatic missense mutations were found in heterozygosis in $11 / 41$ patients with somatotropinomas $(27 \%)$ and in 1/21 (p.R201C) with NFPA (4.8\%) ( $P=0.05)$. Comparing the clinical and laboratory characteristics of patients with somatotropinomas harboring $(+)$ or not $(-)$ GNAS mutations, no significant difference was identified in gender, age of diagnosis, tumor size and extension, and hormonal and tumor remission (Table 2). Expression of PTTG and AIP mRNA and Ki-67 and p53 proteins also did not show significant differences between somatotropinomas GNAS + and GNAS- (Table 2).

\section{AIP variants}

We found a previously described splicing variant c.468 + 15C > T (rs267607274, CS0910309) in the tumor's DNA from a patient with NFPA. This patient was diagnosed at 43 years old and had a null cell macroadenoma extending to the suprasellar region. In silico analysis using HSF) predicted a creation of a new intronic splicing enhancer, but both HSF and NetGene2 tools predicted no probable impact on splicing. Three other AIP polymorphic variants rs641081, rs2276020, and rs35665586 were found in germline and somatic DNA with a minor allelic frequency of $0.171,0.025$, and 0.005 , respectively, similar to $\mathrm{NCBI}$ data bank. No evidence of AIP loss of heterozygosity was observed. 
Table 2. Characteristics of mutated versus non-mutated GNAS patients with somatotropinomas.

\begin{tabular}{lccc}
\hline & GNAS + & GNAS- & P value \\
\hline Sex (female:male) & $7: 4$ & $20: 10$ & 0.856 \\
Age at diagnosis (years) & $37.0 \pm 11.9$ & $41.5 \pm 16.3$ & 0.409 \\
Basal GH (mg/dL) & $37.4(10.9-76.0)$ & $15.1(5.4-69.0)$ & 0.233 \\
Basal IGF-1 (mg/dL) & $1004.9 \pm 257.5$ & $949.7 \pm 291.3$ & 0.583 \\
ULNR IGF-1 & $331.0(272.0-392.7)$ & $388.0(300.0-435.0)$ & 0.377 \\
Tumor size & & & \\
Largest diameter & $2.36 \pm 1.05$ & $2.23 \pm 1.29$ & 0.771 \\
Micro:macro & $1: 10$ & $3: 27$ & 0.930 \\
Invasiveness (yes:no) & $8: 3$ & $17: 13$ & 0.478 \\
Tumor expansion & & & \\
Intrasellar & 2 & 7 & 0.970 \\
Infrasellar + supra/parasellar & 4 & 9 & \\
Parasellar & 1 & 2 & \\
Suprasellar & 1 & 6 & \\
Para + suprasellar & 3 & 6 & 0.000 \\
Remission (yes:no) & & & \\
After SST analogs & $3: 3$ & $10: 9$ & 0.777 \\
After surgery & $4: 6$ & $7: 14$ & 0.364 \\
AIP RQ & $0.56(0.47-0.95)$ & $1.33(1.0-3.8)$ & 0.297 \\
PTTG RQ & $7.77(5.39-12.8)$ & $1.00(1.0-1.0)$ & 0.083 \\
Ki67 index (\%) & $1.7(1.0-4.5)$ & $(1.0 .36-1.00)$ & \\
p53 (\%) & $1.1(1.0-1.4)$ & & \\
\hline
\end{tabular}

Data are reported as means \pm SD and median $\left(25^{\text {th }}\right.$ and $75^{\text {th }}$ percentiles). *Mean, minimum, and maximum values are reported for Ki67 index and p53. GH: growth hormone; IGF-1: insulin-like growth factor-1; ULNR: upper limit of the normal age- and sex-matched range; GNAS: guanine nucleotide-binding protein, alpha stimulating; AIP: aryl hydrocarbon receptor interacting protein; PTTG: pituitary tumor transforming gene; $\mathrm{RQ}$ : relative quantification; SST: stomatostatin. ANOVA, Mann-Whitney $U$ test, Kruskal-Wallis test, Pearson's chi-squared test, and Fisher exact test were used where applicable.

\section{PTTG and AIP mRNA expression}

Gene expression analysis was performed in 43 samples (somatotropinoma, $n=29, N F P A, n=14$ ) with satisfactory RNA quality. PTTG expression level was significantly higher in NFPA compared to somatotropinomas $(P=0.04$, Table 1) and was associated with tumor invasiveness $(P=0.03)$, especially in NFPA $(P=0.02$; Figure 1$)$. There was no difference in the expression of PTTG and AIP in both somatotropinomas and NFPA, and hormonal dosage, age of diagnosis, tumor size, tumor and/or hormonal control, Ki-67 index, and p53 expression (data not shown).

\section{Ki-67 and p53 immunohistochemistry}

Tumor samples for immunohistochemical staining were available from 45 patients (somatotropinoma, $n=27, N F P A$, $\mathrm{n}=18$ ). This analysis showed a Ki-67 labeling index mean of $1.32 \%(1.0-4.5)$ and of $1.1 \%(1.0-1.8)$ for p53 expression. No difference was observed in the Ki-67 and p53 expression levels between somatotropinomas and NFPAs $(P=0.27$ and $P=0.21$, respectively, Table 1 ). In both somatotropinomas and NFPAs, Ki-67 and p53 expressions were not related with patient's age and tumor characteristics such as tumor size, infra-, intra-, para-, and suprasellar extension (data not shown). Neither Ki-67 nor p53 expression were correlated with hormonal levels and radiological recurrence in somatotropinomas and NFPAs, respectively, or tumor invasiveness (Figure 1B).

\section{Discussion}

The present study evaluated clinical, laboratory, and GNAS, AIP, and PTTG molecular data of 62 apparently sporadic pituitary adenomas followed in a single endocrine tertiary-referral center. In line with previous results, GNAS proto-oncogene-activating mutations were the most frequent genetic mutation identified in 27 and $4.8 \%$ of somatotropinomas and NFPA, respectively $(9,12)$. Comparing clinical and laboratory data of GNAS + and GNAS- somatotropinomas patients, no significant difference was observed. These findings are similar to some data in the literature $(7,14-17)$. However, other studies associated the presence of GNAS mutation with smaller (in diameter) and less invasive somatotropinomas (18-20). 

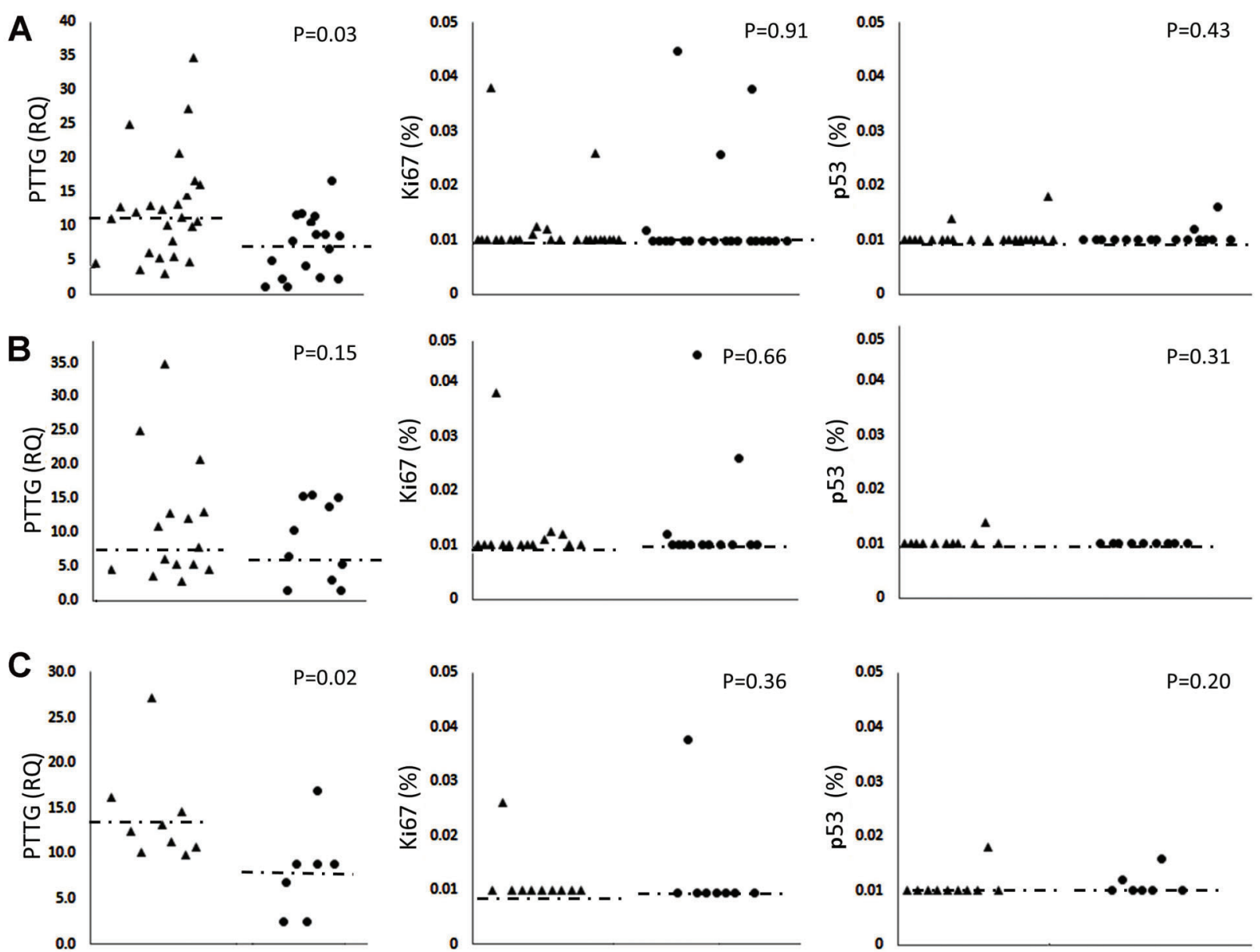

Figure 1. Expression of histological and molecular markers of proliferation/invasion in invasive and non-invasive pituitary adenomas. Graphs represent distributional plot of qPCR results for pituitary tumor transforming gene (PTTG) and immunohistochemical analysis (Ki67 and p53), with the scoring for the respective marker depicted in the $y$-axis. $A$, Somatotropinomas and non-functioning pituitary adenomas (NFPA). B, Somatotropinomas. C, NFPA. Dashed lines: medians; triangles: invasive cases; circles: non-invasive cases. $R Q$ : relative quantification. Mann-Whitney $U$ test was used for statistical analyses.

The lack of phenotype-genotype correlation between GNAS-mutated and non-mutated pituitary adenomas could be explained by modulation of phosphodiesterase enzymes responsible for the hydrolysis of cyclic adenosine monophosphate (21). Persani et al. demonstrated that GNAS + somatotropinomas had an increased activity of phosphodiesterase isoforms in relation to GNASsomatotropinomas (21). Also, the GNAS locus displays a complex genomic imprinting being expressed only from the maternal allele in the pituitary gland (22). Some studies have demonstrated that GNAS loss of methylation at maternal promoter is associated to response to somatostatin analogs and contributes to the pathogenesis of acromegaly $(23,24)$.

Regarding the AIP tumor suppressor gene, we found a very rare c. $468+15 \mathrm{C}>\mathrm{T}$ polymorphic AIP variant in a patient with NFPA. The $c .468+15 C>T$ was previously described in a young female patient with acromegaly due to a macroadenoma (24). According to in silico predictions, the $c .468+15 C>T$ variant has a lower probability to be deleterious. However, considering our results and previous published results, the calculated minor allele frequency (MAF) of this variant in pituitary adenomas was 0.004 , much higher than $\mathrm{MAF}=0.000025$ described by Exome Aggregation Consortium (ExAC; http://exac. broadinstitute.org/) $(25,26)$. Therefore, we speculate that this noncoding nucleotide change could be related with pituitary tumorigenesis of somatotropinomas and NFPA. Additional analyses are essential to determine the real significance of this variant for AIP function.

Usually, AIP loss-of-function mutations are associated with a more aggressive disease and a low probability of surgical remission $(27,28)$. These mutations are uncommon in sporadic pituitary adenomas, but their prevalence 
may increase among young patients: $23.3 \%$ (age at diagnosis $\leqslant 18$ years) and $20.5 \%$ (age at diagnosis $\leqslant 30$ years) $(9,29,30)$. In our study, $34 \%$ of acromegalic patients were diagnosed $\leqslant 30$ years old. Comparing young patients with patients older than 30 years at diagnosis, there was no difference in hormone assessment, tumor size, and response to treatment. Nevertheless, we have not identified AIP mutations in these patients, only very common polymorphic variants. mRNA expression was also evaluated and underexpression of $A I P$ was found in virtually all patients, including in NFPA, but without any correlation with clinical and biological tumor features.

The PTTG expression observed in our cohort was high in almost all patients and was related significantly to invasiveness $(P=0.03)$, particularly for NFPA $(P=0.02)$. In fact, a recent meta-analysis study confirmed high expression levels of PTTG in different pituitary tumors and its correlation with invasiveness and tumor recurrence (31). However, no difference of PTTG levels between invasive and non-invasive somatotropinomas was found in our study $(P=0.141)$. Although some studies showed a higher PTTG expression in acromegalic patients than in NFPA $(31,32)$, we noted a significantly higher expression of PTTG in NFPA $(P=0.04)$, which was in agreement with the higher rate of invasiveness of this tumor subtype $(5,34,35)$.

In the current study, the Ki-67 cell proliferation marker showed positivity of less than $3 \%$ and the immunopositivity of p53 was not statistically significant. These results are in agreement with the literature, in which the majority

\section{References}

1. Aflorei ED, Korbonits M. Epidemiology and etiopathogenesis of pituitary adenomas. J Neurooncol 2014; 117: 379-394, doi: 10.1007/s11060-013-1354-5.

2. Jiang $X$, Zhang $X$. The molecular pathogenesis of pituitary adenomas: an update. Endocrinol Metab (Seoul) 2013; 28: 245-254, doi: 10.3803/EnM.2013.28.4.245.

3. Efstathiadou ZA, Bargiota A, Chrisoulidou A, Kanakis G, Papanastasiou L, Theodoropoulou A, et al. Impact of gsp mutations in somatotroph pituitary adenomas on growth hormone response to somatostatin analogs: a meta-analysis. Pituitary 2015; 18: 861-867, doi: 10.1007/s11102-015-0662-5.

4. McCabe CJ, Khaira JS, Boelaert K, Heaney AP, Tannahill LA, Hussain $S$, et al. Expression of pituitary tumour transforming gene (PTTG) and fibroblast growth factor-2 (FGF-2) in human pituitary adenomas: relationships to clinical tumour behaviour. Clin Endocrinol (Oxf) 2003; 58: 141-150, doi: 10.1046/j.1365-2265.2003.01598.x.

5. Noh TW, Jeong HJ, Lee MK, Kim TS, Kim SH, Lee EJ. Predicting recurrence of nonfunctioning pituitary adenomas. $J$ Clin Endocrinol Metab 2009; 94: 4406-4413, doi: 10.1210/ jc.2009-0471.

6. Wierinckx A, Auger C, Devauchelle P, Reynaud A, Chevallier $P$, Jan $M$, et al. A diagnostic marker set for invasion, proliferation, and aggressiveness of prolactin pituitary tumors. of pituitary adenomas are typically $3 \%$ (35). Immunoexpression of both markers, p53 and Ki-67, was not different between NFPA and somatotropinomas. In addition, the level of expression of Ki-67 and p53 did not show any significant relationship with sex, age (below and above 30 years), characteristics of pituitary adenomas, (type, size, extension, infra- or suprasellar), residual tumor after surgery, and/or hormonal recurrence. These results are in contrast to some studies in which the simultaneous expression of the p53 and $\mathrm{Ki}-67$ markers is related to invasion and tumor aggressiveness, as well as to tumor progression and/or recurrence of pituitary adenomas $(6,12,36,37)$. The relationship between the expression of the p53 protein or Ki-67 cell proliferation marker with the pituitary adenoma has been studied $(37,38)$. However, studies have not clearly shown the importance of Ki-67 and p53 immunohistochemical in the evaluation of predictive and prognostic factors of pituitary adenomas $(38,39)$.

In conclusion, our results are in agreement with previous results that point to PTTG expression as a useful molecular marker for pituitary tumor invasiveness, particularly for NFPA. However, we did not find any evidence for the use of GNAS mutation or immunohistochemical Ki-67 and/or p53 staining as a potential marker to distinguish pituitary tumor behavior.

\section{Acknowledgement}

This work was supported by FAPESP (grant number 2014/10462-4).

Endocr Relat Cancer 2007; 14: 887-900, doi: 10.1677/ERC07-0062.

7. Freda PU, Chung WK, Matsuoka N, Walsh JE, Kanibir MN, Kleinman G, et al. Analysis of GNAS mutations in 60 growth hormone secreting pituitary tumors: correlation with clinical and pathological characteristics and surgical outcome based on highly sensitive GH and IGF-I criteria for remission. Pituitary 2007; 10: 275-282, doi: 10.1007/s11102-0070058-2.

8. Katznelson L, Laws Jr ER, Melmed S, Molitch ME, Murad $\mathrm{MH}$, Utz A, et al. Acromegaly: an endocrine society clinical practice guideline. J Clin Endocrinol Metab 2014; 99: 39333951, doi: 10.1210/jc.2014-2700.

9. Cazabat L, Libè R, Perlemoine K, René-Corail F, Burnichon N, Gimenez-Roqueplo AP, et al. Germline inactivating mutations of the aryl hydrocarbon receptor-interacting protein gene in a large cohort of sporadic acromegaly: mutations are found in a subset of young patients with macroadenomas. Eur J Endocrinol 2007; 157: 1-8, doi: 10.1530/EJE-07-0181.

10. Clementi E, Malgaretti N, Meldolesi J, Taramelli R. A new constitutively activating mutation of the Gs protein alpha subunit-gsp oncogene is found in human pituitary tumours. Oncogene 1990; 5: 1059-1061. 
11. Livak KJ, Schmittgen TD. Analysis of relative gene expression data using real-time quantitative PCR and the 2 (-Delta Delta C(T)) Method. Methods 2001; 25: 402-408, doi: 10.1006/meth.2001.1262.

12. Thapar K, Kovacs K, Scheithauer BW, Stefaneanu L, Horvath E, Pernicone PJ et al. Proliferative activity and invasiveness among pituitary adenomas and carcinomas: an analysis using the MIB-1 antibody. Neurosurgery 1996; 38: 99-106; discussion 106-107, doi: 10.1097/00006123199601000-00024.

13. Landis CA, Masters SB, Spada A, Pace AM, Bourne HR, Vallar L. GTPase inhibiting mutations activate the alpha chain of $G$ s and stimulate adenylyl cyclase in human pituitary tumours. Nature 1989; 340: 692-696, doi: 10.1038/ 340692a0.

14. Yang I, Park S, Ryu M, Woo J, Kim S, Kim J, et al. Characteristics of gsp-positive growth hormone-secreting pituitary tumors in Korean acromegalic patients. Eur $J$ Endocrinol 1996; 134: 720-726, doi: 10.1530/eje.0.134 0720.

15. Mendoza V, Sosa E, Espinosa-de-Los-Monteros AL, Salcedo M, Guinto G, Cheng S, et al. GSPalpha mutations in Mexican patients with acromegaly: potential impact on long term prognosis. Growth Horm IGF Res 2005; 15: 28-32, doi: 10.1016/j.ghir.2004.10.001.

16. Lania A, Spada A. G-protein and signalling in pituitary tumours. Horm Res 2009; 71 Suppl 2: 95-100, doi: 10.1159/ 000192446.

17. Yasufuku-Takano J, Takano K, Morita K, Takakura K, Teramoto A, Fujita T. Does the prevalence of gsp mutations in $\mathrm{GH}$-secreting pituitary adenomas differ geographically or racially? Prevalence of gsp mutations in Japanese patients revisited. Clin Endocrinol (Oxf) 2006; 64: 91-96, doi: 10.1111/j.1365-2265.2005.02423.x.

18. Landis CA, Harsh G, Lyons J, Davis RL, McCormick F, Bourne HR. Clinical characteristics of acromegalic patients whose pituitary tumors contain mutant Gs protein. J Clin Endocrinol Metab 1990; 71: 1416-1420, doi: 10.1210/jcem71-6-1416.

19. Shi Y, Tang D, Deng J, Su C. Detection of gsp oncogene in growth hormone-secreting pituitary adenomas and the study of clinical characteristics of acromegalic patients with gsppositive pituitary tumors. Chin Med J (Engl) 1998; 111: 891-894.

20. Buchfelder M, Fahlbusch R, Merz T, Symowski H, Adams EF. Clinical correlates in acromegalic patients with pituitary tumors expressing GSP oncogenes. Pituitary 1999; 1: 181185, doi: 10.1023/A:1009905131334.

21. Persani L, Borgato S, Lania A, Filopanti M, Mantovani G, Conti M, et al. Relevant cAMP-specific phosphodiesterase isoforms in human pituitary: effect of Gs(alpha) mutations. J Clin Endocrinol Metab 2001; 86: 3795-3800, doi: 10.1210/ jcem.86.8.7779.

22. Chen M, Wang J, Dickerson KE, Kelleher J, Xie T, Gupta D, et al. Central nervous system imprinting of the $G$ protein $\mathrm{G}(\mathrm{s})$ alpha and its role in metabolic regulation. Cell Metab 2009; 9: 548-555, doi: 10.1016/j.cmet.2009.05.004.

23. Picard C, Silvy M, Gerard C, Buffat C, Lavaque E, FigarellaBranger D, et al. Gs alpha overexpression and loss of Gs alpha imprinting in human somatotroph adenomas: association with tumor size and response to pharmacologic treatment. Int J Cancer 2007; 121: 1245-1252, doi: 10.1002/ ijc.22816.

24. Hayward BE, Barlier A, Korbonits M, Grossman AB, Jacquet $P$, Enjalbert $A$, et al. Imprinting of the $G(s)$ alpha gene GNAS1 in the pathogenesis of acromegaly. $J$ Clin Invest 2001; 107: R31-36, doi: 10.1172/JCl11887.

25. Fajardo-Montañana $C$, Daly AF, Riesgo-Suárez $P$, GómezVela J, Tichomirowa MA, Camara-Gómez R, et al. [AIP mutations in familial and sporadic pituitary adenomas: local experience and review of the literature] [article in Spanish]. Endocrinol Nutr 2009; 56: 369-377, doi: 10.1016/S15750922(09)72456-8.

26. Tichomirowa MA, Barlier A, Daly AF, Jaffrain-Rea ML, Ronchi C, Yaneva M, et al. High prevalence of AIP gene mutations following focused screening in young patients with sporadic pituitary macroadenomas. Eur $\mathrm{J}$ Endocrinol 2011; 165: 509-515, doi: 10.1530/EJE-11-0304.

27. Chahal HS, Chapple JP, Frohman LA, Grossman AB, Korbonits M. Clinical, genetic and molecular characterization of patients with familial isolated pituitary adenomas (FIPA). Trends Endocrinol Metab 2010; 21: 419-427, doi: 10.1016/j.tem.2010.02.007.

28. Daly AF, Tichomirowa MA, Petrossians P, Heliövaara E, Jaffrain-Rea ML, Barlier A, et al. Clinical characteristics and therapeutic responses in patients with germ-line AIP mutations and pituitary adenomas: an international collaborative study. J Clin Endocrinol Metab 2010; 95: E373383, doi: 10.1210/jc.2009-2556.

29. Cazabat L, Bouligand J, Salenave S, Bernier M, Gaillard S, Parker $F$ et al. Germline AIP mutations in apparently sporadic pituitary adenomas: prevalence in a prospective single-center cohort of 443 patients. J Clin Endocrinol Metab 2012; 97: E663-670, doi: 10.1210/jc.2011-2291.

30. Barlier A, Vanbellinghen JF, Daly AF, Silvy M, Jaffrain-Rea $\mathrm{ML}$, Trouillas $\mathrm{J}$, et al. Mutations in the aryl hydrocarbon receptor interacting protein gene are not highly prevalent among subjects with sporadic pituitary adenomas. J Clin Endocrinol Metab 2007; 92: 1952-1955, doi: 10.1210/ jc.2006-2702.

31. Li Y, Zhou LP, Ma P, Sui CG, Meng FD, Tian X, et al. Relationship of PTTG expression with tumor invasiveness and microvessel density of pituitary adenomas: a metaanalysis. Genet Test Mol Biomarkers 2014; 18: 279-285, doi: $10.1089 / \mathrm{gtmb} .2013 .0447$.

32. Hunter JA, Skelly RH, Aylwin SJ, Geddes JF, Evanson J, Besser GM, et al. The relationship between pituitary tumour transforming gene (PTTG) expression and in vitro hormone and vascular endothelial growth factor (VEGF) secretion from human pituitary adenomas. Eur $J$ Endocrinol 2003; 148: 203-211, doi: 10.1530/eje.0.1480203.

33. Wierzbicka-Tutka I, Sokołowski G, Bałdys-Waligórska A, Adamek D, Radwańska E, Gołkowski F. PTTG and Ki-67 expression in pituitary adenomas. Przegl Lek 2016; 73: 53-58.

34. Zhang X, Horwitz GA, Heaney AP, Nakashima M, Prezant $T R$, Bronstein MD, et al. Pituitary tumor transforming gene (PTTG) expression in pituitary adenomas. J Clin Endocrinol Metab 1999; 84: 761-767, doi: 10.1210/jcem.84.2.5432.

35. Trouillas J, Roy P, Sturm N, Dantony E, Cortet-Rudelli C, Viennet $\mathrm{G}$, et al. A new prognostic clinicopathological classification of pituitary adenomas: a multicentric case-control study of 410 patients with 8 years post-operative follow-up. 
Acta Neuropathol 2013; 126: 123-135, doi: 10.1007/s00401013-1084-y.

36. Thapar K, Scheithauer BW, Kovacs K, Pernicone PJ, Laws ER. p53 expression in pituitary adenomas and carcinomas: correlation with invasiveness and tumor growth fractions. Neurosurgery 1996; 38: 765-770; discussion 770-761, doi: 10.1227/00006123-199604000-00027.

37. Salehi F, Agur A, Scheithauer BW, Kovacs K, Lloyd RV, Cusimano M. Ki-67 in pituitary neoplasms: a review-part I. Neurosurgery 2009; 65: 429-437; discussion 437, doi: 10.1227/01.NEU.0000349930.66434.82.
38. Hadzhiyanev A, Ivanova R, Nachev E, Elenkova A, Yaneva $M$, Zaharieva $S$, et al. Evaluation of prognostic utility of MIB-1 and p53 expression in pituitary adenomas: correlations with clinical behaviour and follow-up results. Biotechnol Biotechnol Equip 2014; 28: 502-507, doi: 10.1080/13102 818.2014.932510.

39. Sadeghipour A, Mahouzi L, Salem MM, Ebrahim-Nejad S, Asadi-Lari M, Radfar A, et al. Ki67 labeling correlated with invasion but not with recurrence. Appl Immunohistochem Mol Morphol 2017; 25: 341-345, doi: 10.1097/PAI.0000 000000000303. 